\title{
Time-Domain Tools for the Investigation of Gain-Quenched Laser Logic
}

T.C. Bond, J.K. Kallman

This article was submitted to 2003 International Semiconductor Device Research Symposium, Washington, D.C., December 10-12, 2003

\section{August 20, 2003}

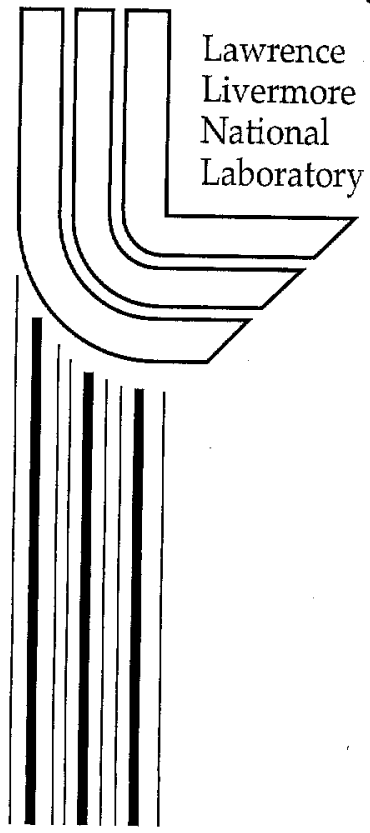




\section{DISCLAIMER}

This document was prepared as an account of work sponsored by an agency of the United States Government. Neither the United States Government nor the University of California nor any of their employees, makes any warranty, express or implied, or assumes any legal liability or responsibility for the accuracy, completeness, or usefulness of any information, apparatus, product, or process disclosed, or represents that its use would not infringe privately owned rights. Reference herein to any specific commercial product, process, or service by trade name, trademark, manufacturer, or otherwise, does not necessarily constitute or imply its endorsement, recommendation, or favoring by the United States Government or the University of California. The views and opinions of authors expressed herein do not necessarily state or reflect those of the United States Government or the University of California, and shall not be used for advertising or product endorsement purposes.

This is a preprint of a paper intended for publication in a journal or proceedings. Since changes may be made before publication, this preprint is made available with the understanding that it will not be cited or reproduced without the permission of the author.

This report has been reproduced directly from the best available copy.

Available electronically at http://www.doc.gov/bridge

Available for a processing fee to U.S. Department of Energy

And its contractors in paper from

U.S. Department of Energy

Office of Scientific and Technical Information

P.O. Box 62

Oak Ridge, TN 37831-0062

Telephone: (865) 576-8401

Facsimile: (865) 576-5728

E-mail: reports@adonis.osti.gov

Available for the sale to the public from

U.S. Department of Commerce

National Technical Information Service

5285 Port Royal Road

Springfield, VA 22161

Telephone: (800) 553-6847

Facsimile: (703) 605-6900

E-mail: orders@ntis.fedworld.gov

Online ordering: http://www.ntis.gov/ordering.htm

OR

Lawrence Livermore National Laboratory

Technical Information Department's Digital Library

http://www.llnl.gov/tid/Library.html 


\section{Time-Domain Tools for the Investigation of Gain-Quenched Laser Logic \\ Tiziana C. Bond, Jeffrey K. Kallman \\ Lawrence Livermore National Laboratory, Livermore, $C A$}

\section{Abstract}

Integrated all-optical logic gates that exploit the optical gain quenching effect in laterally optically pumped semiconductor multi-section edge-emitting lasers (SMEELs) are described. An accurate 2D timedomain (TD) model was implemented to investigate the gates' gain, modulation depth, and speed.

\section{Summary}

Gain Quenched Laser Logic (GQLL) offer the potential of integrating several processing functions on the same chip and has many applications for all-optical high-speed switching. Lasers with optical gain control capable of routing and logic functions ${ }^{1,2,3}$ have been demonstrated via the gain quenching effect ${ }^{4}$. In an inverter gate the laser output power is quenched when an optical input signal laterally coupled to the laser (control region) is high. NOR and NAND gates are achievable by adding other arms. The basic configuration of a GQLL device is schematically depicted in Fig. 1. The Boolean completeness of this technology, the recent achievement in high laser modulation bandwidths, and the possibility of integrating lasers and passive waveguide interconnects progress using standard microelectronics fabrication techniques ${ }^{6}$, makes GQLL the basis for a high-speed photonic logic family.

\section{Numerical Models}

Several models have been developed for analyzing laser nonlinear differential rate equations, but they are often reduced to a lumped parameter treatment or are implemented in the steady state rather than the transient regime, particularly in the case of optically quenched lasers ${ }^{7}$. Given the promise of this technology, accurate TD modeling tools are important to minimize design cycle time and cost.

We developed a suite of simulators for the analysis and design of SMEELs. We have developed lumped parameter, $1 \mathrm{D}$, and $2 \mathrm{D}$ codes and validated them against existing results. ${ }^{8,9}$

Here we focus on our 2D model, solved using an FFT based BPM in conjunction with the method of characteristics ${ }^{10}$, which includes multiple controls, multiple wavelengths, gain saturation, a stochastic model of amplified spontaneous emission, and spatial hole burning, through carrier diffusion and multimode analysis.

Starting from the scalar wave equation, we assume fields of the form

$$
E(x, z, t)=\emptyset^{+}(x, z, t) e^{i\left(\omega t-k_{0} n_{0} z\right)}+\emptyset^{-}(x, z, t) e^{i\left(\omega t+k_{0} n_{0} z\right)}
$$

Using the slowly varying envelope approximation yields

$$
2 i k_{0}\left(\frac{n^{2}}{c}-\frac{\partial \psi^{ \pm}}{\partial t} \pm n_{0} \frac{\partial \psi^{ \pm}}{\partial z}\right)=\nabla_{\perp}^{2} \psi^{ \pm}+k_{0}^{2}\left(n^{2}-n_{0}^{2}\right) \psi^{ \pm}
$$

The method of characteristics allows us to combine the partial derivatives in time and $z$ to obtain

$$
\frac{d \psi^{ \pm}}{d z}=\frac{ \pm 1}{2 i k_{0} n_{0}}\left[\nabla_{\perp}^{2}+k_{0}^{2}\left(n^{2}-n_{0}^{2}\right)\right] \psi^{ \pm}
$$

These can be solved using an FFT based BPM solver. We can model gain as either a variation in the imaginary part of the index of refraction, or add it in as an additional separate factor. Carrier density is modeled at every active simulation pixel in the $(\mathrm{z}, \mathrm{x})$ plane as follows

$$
\frac{\partial N}{\partial t}=\frac{\eta J(z, x, t)}{e d}-A N-B N^{2}-C N^{3}-P G(N)+D \frac{\partial^{2} N}{\partial x^{2}}
$$

Carrier density at a computational pixel is gained through current injection, lost due to various decay mechanisms, and may be gained or lost due to diffusion and interaction with the photon density of the left and right going scalar field envelopes.

\section{GQLL Gates}

An investigation of the parameter space was carried out to determine the inverter modulation efficiency (level restoring), gain (fan-out), and time response (clock-rate). We observed that the best gain and modulation depth are obtained using long control regions, wide lasers, and operating close to threshold, with a control power close to the unquenched power. We also verified that optical quenching is a particular case of gain-lever effect." We have shown that although GQLL gates are possible, those with gain greater than one are not feasible. For example a wide laser $(>10 \mu \mathrm{m})$ requiring high current $(>10 \mathrm{~mA})$, would do the $\mathrm{job}^{\mathbf{1 2}}$, but a microcavity $(\mathrm{L}=16 \mu \mathrm{m})$ with very asymmetric mirrors reflectivity $(1: 66)$, would require very high current densities in the control region. 


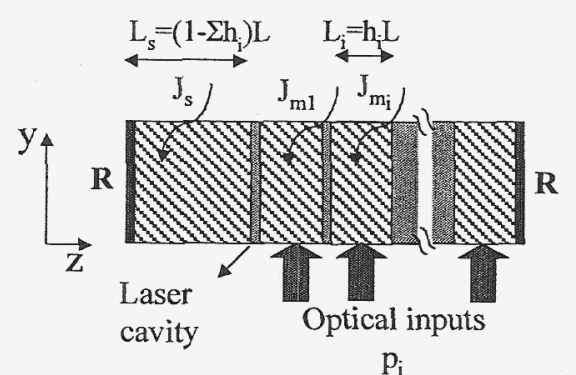

Fig. 1 Scheme of a SMEEL.

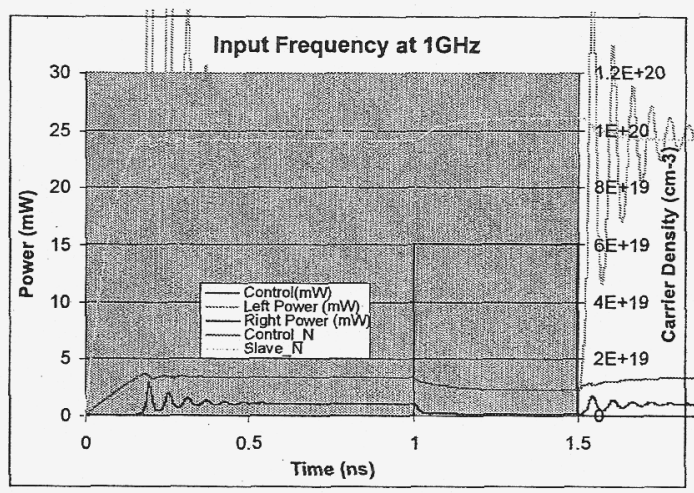

Fig. 2 Output powers and carrier densities for a microcavity laser. A Gain $>1$ is observed for the low reflectivity facet.

NOR gate behavior is demonstrated in Fig. 3. In the main window the laser running longitudinally is visible together with two lateral input waveguides. Once the laser has reached its steady state, the controls are applied. When two controls are turned on simultaneously a stronger modulation depth is induced.

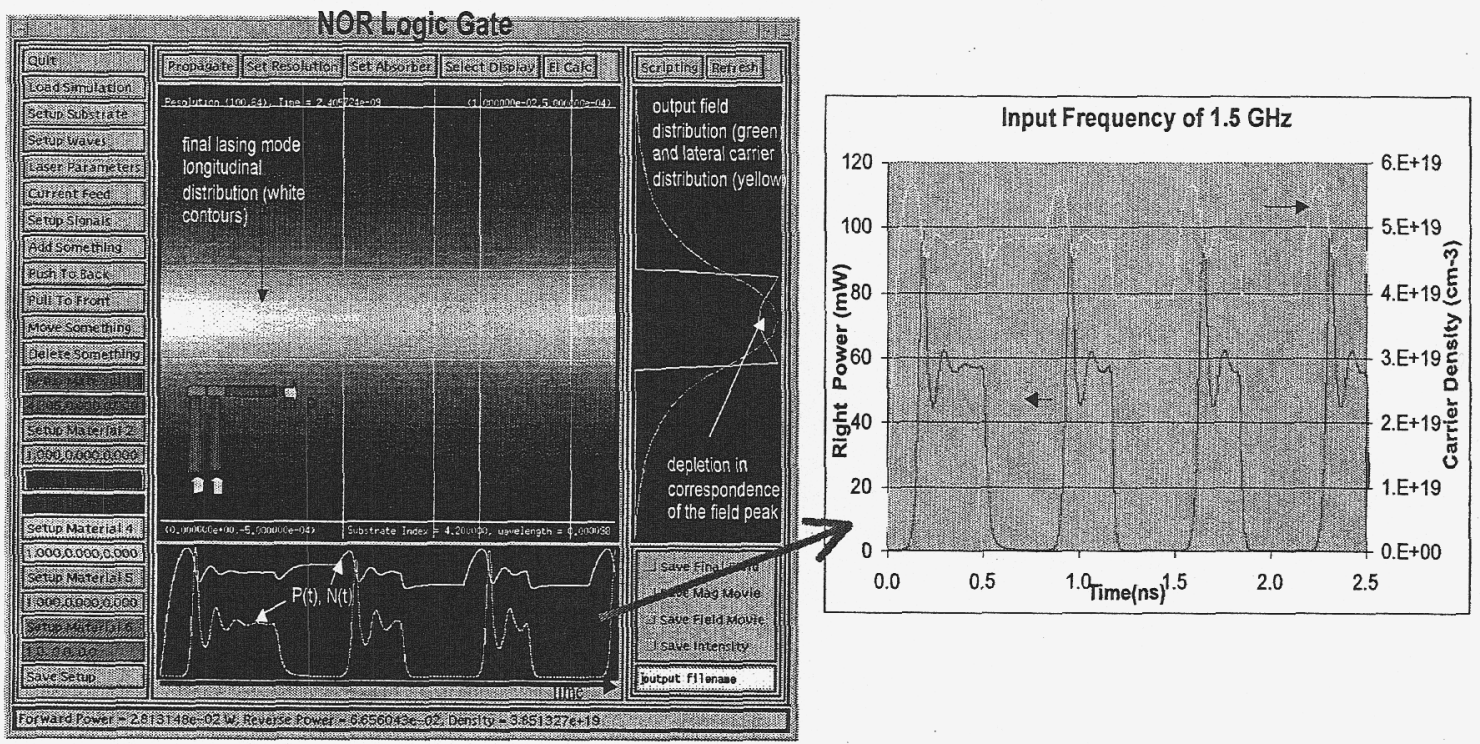

Fig. 3.C++-based Graphical User Interface for 2D model. Central window: final longitudinal field distribution. Lateral window: output field distribution (green) and lateral carrier distribution (yellow) showing spatial hole burning. Bottom window: lasing power and average carrier density as a function of time.

We currently believe nonlinear effects are responsible of the inverter behavior with high gain observed at currents much higher than threshold ${ }^{3}$. We are expanding our code to include free-carrier absorption effects and polarization dependence, which will be described in future communications.

This work was performed under the auspices of the U.S. Department of Energy by the University of California, Lawrence Livermore National Laboratory under Contract W-7405-Eng-48.

${ }^{1}$ A.B. Fowler, vol.3, no.1, July $1963, \mathrm{pp} .1-3$.

${ }^{2}$ F. Robert et al., Appl. Phys. Lett., vol. 71, no.21, Nov. 1997, pp. 3039-41.

${ }^{3}$ J.L. Fitz et al., IEEE Photon. Technol. Lett., vol.13, no. 5, May 2001, pp. 478-80.

${ }^{4} \mathrm{H}$. Kawaguchi, Bistabilities and Nonlinearities in Laser Diodes, Boston MA, Artech, 1994, pp.80-81

${ }^{5}$ W.J. Grande et al., Appl. Phys. Lett., vol. 51, no. 22, Nov. 1987, pp. 1780-2.

${ }^{6}$ X. Zhang t al., IEEE Journ. Select. Top. Quant. Electron., vol. 3, no.2, April 1997, pp. 309-14.

${ }^{7}$ M.A. Parker et al.,Appl. Phys. Lett., vol. 70, no.2, Jan. 1997, pp.146-8.

${ }^{8}$ G. A. Vawter et al, IEEE LEOS Annual Meeting, Conference Proceedings, (IEEE, San Francisco, 1999), pp. 531-2.

${ }^{9}$ L.A. Coldren et al., Diode Laser and Photonic Integrated Circuits (Wiley Series, 1995).

${ }^{10}$ M.D. Feit et al, J. Opt. Soc. Am. B, Vol. 7, No. 10, pp. 2048-2060, October 1990.

${ }^{11}$ K. J. Vahala et al., Appl. Phys. Lett., vol. 54, no. 25,pp. 250608 (June 1989).

${ }^{12}$ T. C. Bond et al., OSA Annual Meeting 2001. 